\title{
Differential effects of LH-RH immunoneutralization on LH and FSH secretion in the ewe
}

\author{
H. M. Fraser and A. S. McNeilly \\ M.R.C. Reproductive Biology Unit, Centre for Reproductive Biology, 37 Chalmers Street, \\ Edinburgh EH3 9EW, U.K.
}

\begin{abstract}
Summary. Neutralization of LH-RH by injection of an ovine antiserum to LH-RH in ewes during the late follicular phase of the oestrous cycle resulted in an immediate blockade of pulsatile secretion of LH. Plasma concentrations of FSH gradually rose in the antiserum-treated ewes during the 36-h study period but levels declined in control ewes. These results show that, in the ewe, pulsatile LH secretion is dependent on LH$\mathrm{RH}$ from the hypothalamus, while FSH is largely unresponsive to short-term reduction of LH-RH stimulation. Since reduction in $\mathbf{L H}$ secretion is likely to reduce ovarian function, the changes in FSH secretion may be attributed to the removal of a negative feedback influence of an ovarian factor, perhaps oestradiol, on FSH secretion.
\end{abstract}

\section{Introduction}

Passive immunoneutralization of luteinizing hormone-releasing hormone (LH-RH) prevents the preovulatory surge of luteinizing hormone (LH) and follicle-stimulating hormone (FSH) in the rat (Koch, Chobsieng, Zor, Fridkin \& Lindner, 1973; Arimura, Debeljuk \& Schally, 1974; Kerdelhue, Catin, Kordon \& Jutisz, 1976; Kawakami \& Higuchi, 1979), hamster (de la Cruz, Arimura, de la Cruz \& Schally, 1976) and ewe (Narayana \& Dobson, 1979; Fraser \& McNeilly, 1982). However, little is known about the changes associated with neutralization of LH-RH on tonic gonadotrophin secretion in the intact female. In the present report, we investigated the effects of LH-RH antibodies on gonadotrophin secretion during the late follicular phase of the oestrous cycle in the ewe, with particular reference to the role of $\mathrm{LH}-\mathrm{RH}$ in causing pulsatile release of $\mathrm{LH}$, and the differences in the control of LH and FSH. In addition, since administration of antibodies to LH$\mathrm{RH}$ in the rat has been reported to cause prolonged cyclic failure associated with hyperprolactinaemia (Kerdelhue et al., 1976), we examined the long-term effects of the antibodies on oestrous cycles and plasma prolactin concentrations.

\section{Materials and Methods}

Eleven Scottish Blackface ewes (4-5 years old, $52-57 \mathrm{~kg}$ body weight) with regular oestrous cycles were treated with progestagen-impregnated vaginal pessaries (Chronogest, Intervet Laboratories, Cambridge, U.K.) to synchronize cycles during the mid-breeding season in January. After 12 days the pessaries were withdrawn and a catheter ending in a three-way tap was inserted into the jugular vein and the ewes were transferred to individual crates indoors. At $24 \mathrm{~h}$ after pessary withdrawal blood samples were taken at 10-min intervals for $4 \mathrm{~h}$. At this time 5 ewes were given an intravenous infusion of $100 \mathrm{ml}$ ovine antiserum to bovine serum albumin over a 20 -min period and 6 ewes were 
infused with $100 \mathrm{ml}$ ovine antiserum to LH-RH. Blood samples were collected at 10-min intervals for a further $4 \mathrm{~h}$ and at hourly intervals until $36 \mathrm{~h}$ after antiserum injection.

The catheters were removed and the animals returned to the pasture. Blood samples were taken by jugular venepuncture on Days 3, 4 and 7 after withdrawal of progestagen and at intervals of 2-3 days for 87 days thereafter. Oestrus was detected by running the ewes with a raddled vasectomized ram until the end of the breeding season and to determine the onset of the following breeding season.

Plasma was stored at $-20^{\circ} \mathrm{C}$ until required for radioimmunoassay of $\mathrm{LH}$ and FSH in the sequential blood samples and $\mathrm{LH}, \mathrm{FSH}$, prolactin, progesterone and $\mathrm{LH}-\mathrm{RH}$ antibody titre in the daily samples.

\section{Antiserum}

The LH-RH antiserum used to treat intact ewes was a pool obtained from various blood samples from Ewe 39 immunized against LH-RH conjugated to BSA (Fraser, Clarke \& McNeilly, 1981). The properties of this antiserum have been described previously (Lincoln \& Fraser, 1979; Fraser \& McNeilly, 1982). Control antiserum was obtained from a ewe immunized against BSA.

\section{Radioimmunoassays}

The concentration of $\mathrm{LH}$ was determined by radioimmunoassay (Martensz, Baird, Scaramuzzi \& Van Look, 1976) of duplicate quantities of plasma and results were expressed in terms of ng NIHLH-S $14 / \mathrm{ml}$. The sensitivity of the assay was $0.3 \mathrm{ng} / \mathrm{ml}$ and the intra- and inter-assay coefficients of variation were 8 and $10 \%$ respectively. FSH was measured in duplicate using the radioimmunoassay described by McNeilly, McNeilly, Walton \& Cunningham (1976) and results were expressed as ng NIH-FSH-S10/ml. Assay sensitivity was $20 \mathrm{ng} / \mathrm{ml}$ with intra- and inter-assay coefficients of variation being 9 and $12 \%$ respectively. Prolactin was measured in duplicate quantities of plasma by radioimmunoassay (McNeilly \& Andrews, 1974) and results were expressed in terms of ng NIHPRL-S6/ml. This assay had a sensitivity of $0.05 \mathrm{ng} / \mathrm{ml}$ and intra- and inter-assay coefficients of variation of 8 and $11 \%$ respectively. Progesterone was measured by radioimmunoassay as described previously (Scaramuzzi, Corker, Young \& Baird, 1975) with a detection limit of $0.2 \mathrm{ng} / \mathrm{ml}$ and intraand inter-assay coefficients of variation of 10 and $12 \%$ respectively. LH-RH antibody titre of the plasma from the ewes after passive immunization was assessed as before (Clarke, Fraser \& McNeilly, 1978) and expressed as the initial dilution of plasma binding $33 \%$ of a constant amount of ${ }^{125}$ I-labelled LH-RH.

\section{Statistical analysis}

A rise in $\mathrm{LH}$ was considered to be a pulse if the value of two consecutive samples was greater than the mean of the two previous samples (basal value) and the value of at least one of the peak samples exceeded the mean basal value by more than twice the co-efficient of variation of the assay (Bäckström, McNeilly, Leask \& Baird, 1982).

Because of considerable individual variation between animals, plasma concentrations of FSH were assessed as the percentage change from the mean of the 4-h preinjection value for each ewe. Differences in FSH between control and antibody-treated animals during the period 5-30 h after antibody injection were analysed by Student's $t$ test using the mean value over this time period for each individual ewe. Student's $t$ test was also used for analysis of the long-term effects on LH and FSH. 


\section{Results}

Short-term effects on $\mathrm{LH}$ and FSH secretion

The effects of antiserum injection on pulsatile LH release in the intact ewes are shown in Textfig. 1. In all ewes clear LH pulses occurred at a frequency of one per $60-80 \mathrm{~min}$. In the 5 control ewes, injection of antiserum to BSA had no effect on LH pulses while in all 6 ewes treated with the LH-RH antiserum LH pulses were abolished. Because of the high frequency of withdrawal of blood samples we observed the effects of the antibody on different stages of an LH pulse (Text-fig. 1). In Text-fig. 1(b), for example, the LH pulse appeared to be due just at the time of antibody administration but the expected pulse failed to occur, indicating that the antibody had intercepted the LH-RH from the hypothalamus, causing an immediate neutralization of its action.

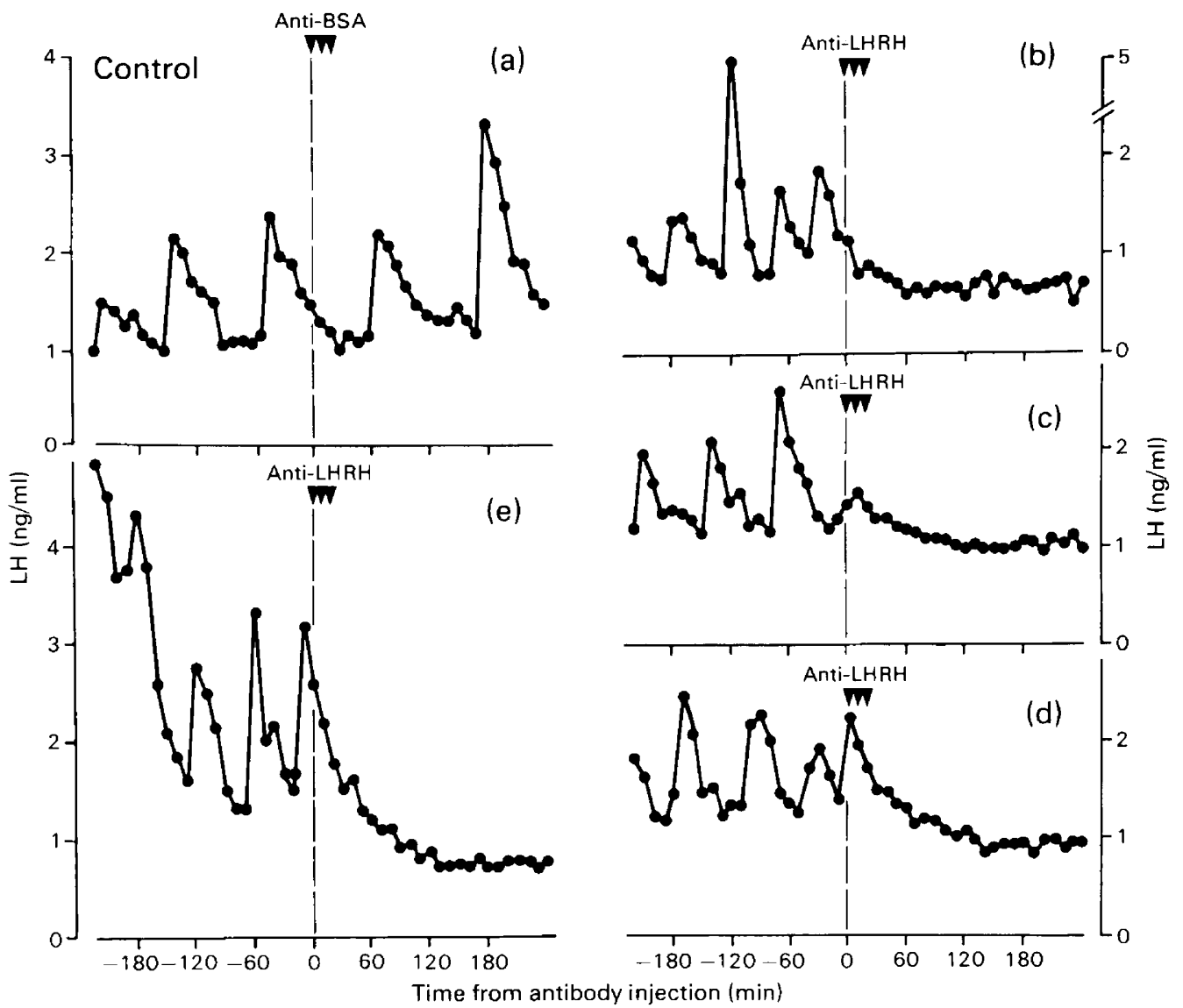

Text-fig. 1. Effect of an i.v. injection of (a) antiserum to BSA (control) or (b, c, d, e) antiserum to LH-RH on plasma LH concentrations during the follicular phase of the oestrous cycle in the ewe. The LH-RH antiserum injection in the 4 treated ewes is at different times in relation to the LH pulse.

Mean values for plasma LH and FSH concentrations during the 36-h period after antibody injection are shown in Text-fig. 2. In the control animals LH pulses continued while in the LH-RH antibody-treated ewes $\mathrm{LH}$ pulses were abolished. In contrast, the antibodies to LH-RH did not cause a decline in pituitary output of FSH during the 36 -h sampling period. The mean \pm s.e.m. plasma concentrations of FSH representing the $100 \%$ preinjection values were $89 \pm 15 \mathrm{ng} / \mathrm{ml}$ for 
controls and $70 \pm 8 \mathrm{ng} / \mathrm{ml}$ for the treated ewes. In the controls, FSH concentrations gradually declined during this period (1-2 days after progestagen withdrawal) while in the LH-RH antibodytreated animals there was a small increase in FSH concentrations during the period 5-30 h after antibody administration (Text-fig. 2). During this period, plasma FSH levels in LH-RH antibody treated ewes were significantly higher $(P<0.01)$ than in controls $(t=3.7$; d.f. $=9)$.

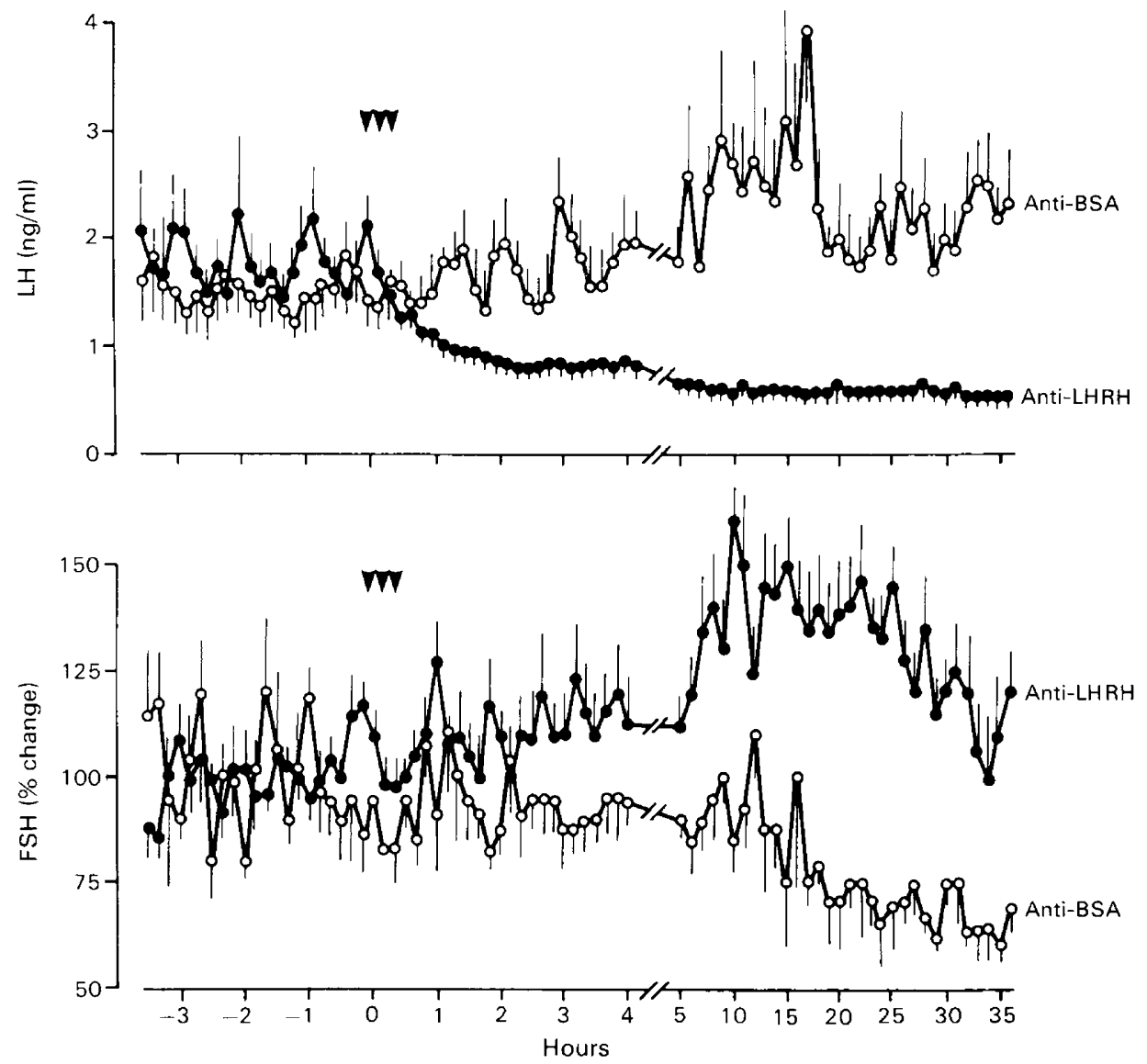

Text-fig. 2. Effects of an i.v. injection (arrows) of antiserum to BSA (control) or antiserum to LH-RH on the mean plasma concentrations of LH and FSH during the follicular phase of the oestrous cycle in the ewe. The oestrous cycles had been synchronized using progestagenimpregnated pessaries which were removed $28 \mathrm{~h}$ before administration of antiserum. Values are mean \pm s.e.m. for 5 control ewes and 6 LH-RH antibody-treated ewes.

\section{Long-term effects of LH-RH immunoneutralization}

All control animals demonstrated a clear elevation of plasma progesterone beginning 7-9 days after progestagen withdrawal, indicating that a normal ovulation had occurred (Text-fig. 3). In contrast, none of the treated ewes showed a rise in progesterone. Ovulation was presumably preceded by an LH surge in control animals but this was only detected in one ewe on Day 4, probably occurring in other control ewes on Days 5 and 6 when blood samples were not taken. An earlier onset of the LH surge, which would have been detected during our study period, had been anticipated but this may have been delayed by use of progestagen. However, we have already established that the LH surge is prevented in the ewe by this antiserum (Fraser \& McNeilly, 1982). 
Behavioural oestrus was not studied before the ovulation immediately after treatment, but all control ewes demonstrated oestrus 20-22 days after withdrawal of the progestagen pessary, while none of the LH-RH antiserum-treated ewes came into heat during this period.

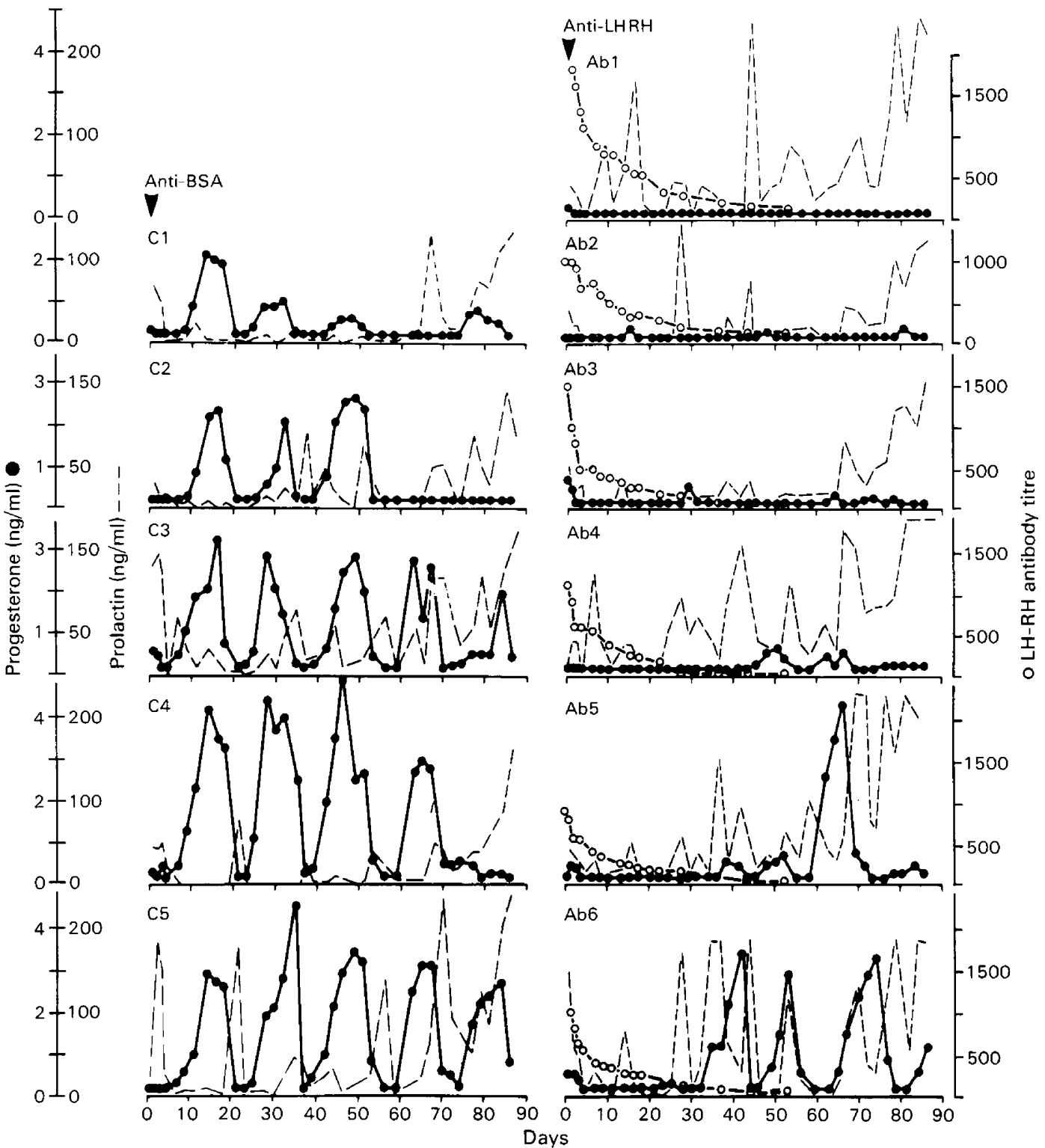

Text-fig. 3. Long-term effects of a single injection of antiserum to BSA or antiserum to LH-RH on plasma levels of progesterone, prolactin and LH-RH antibody titre. Results for the individual animals in each group have been arranged according to descending order of cyclic activity.

The control ewes continued to cycle for various times until the end of the breeding season, 4 of the 5 ewes having at least 2 further normal cycles (Text-fig. 3). In the treated ewes, LH-RH antibody titre declined rapidly during the first 7 days after administration, this period representing the approximate half-disappearance time in the circulation. Thereafter levels fell more slowly, 
reaching titres of $<1: 100$ by 30-40 days (Text-fig. 3). In 3 of the 6 ewes there was no evidence of return of ovulation during the remainder of the breeding season. Ewe 4 had progesterone levels indicating 2 ovulations with an inadequate luteal phase, ewe 5 showed evidence of an inadequate CL followed by a normal cycle, while the remaining animal began normal cycles by Day 32 (Textfig. 3). LH levels remained suppressed $(P<0.05)$ during the first 3 weeks after antibody treatment, but then returned to within the normal range. Plasma concentrations of FSH were similar in both groups during this period (data not shown).

Control ewes demonstrated elevations of plasma prolactin on a number of occasions, most often before ovulation (Text-fig. 3). Ewes treated with LH-RH antiserum also showed variable elevations in prolactin concentrations associated with anovulation. These elevations were not sustained nor did they bear any obvious relation to whether or not cycles were re-established. The onset of the following breeding season was similar in both groups, all ewes having demonstrated behavioural oestrus by October.

\section{Discussion}

By taking sequential blood samples at 10-min intervals in ewes producing $\mathrm{LH}$ pulses at $60-80$-min intervals we have been able to demonstrate conclusively that i.v. injection of antibodies to LH-RH leads to the immediate neutralization of LH-RH. In one ewe, the antibodies were administered when a pulse of $\mathrm{LH}$ was imminent. The fact that the $\mathrm{LH}$ pulse was not observed strongly indicates that the antibodies intercepted and neutralized a pulse of LH-RH which would have preceded it. These results confirm and extend previous studies on the effects of immunoneutralization of $\mathrm{LH}$ RH on LH pulses in the ram (Lincoln \& Fraser, 1979), ovariectomized rats (Snabes \& Kelch, 1979) and castrated rat (Ellis, Desjardins \& Fraser, 1983). This conclusion is supported by the demonstration that in ovariectomized ewes LH pulses are preceded or accompanied by LH-RH pulses measured by radioimmunoassay of hypophysial portal blood (Clarke \& Cummins, 1982; Levine, Pau, Ramirez \& Jackson, 1982).

The fact that the LH-RH antibodies failed to reduce secretion of FSH during the 36-h study period shows that, unlike LH, secretion of FSH is not dependent on short-term changes in LH-RH release. Similar effects have been observed in other situations. Although injection of LH-RH antibodies before the preovulatory gonadotrophin surges in the rat and ewe will prevent the surge of FSH as well as LH (Koch et al., 1973; Arimura et al., 1974; Narayana \& Dobson, 1979; Blake \& Kelch, 1981; Hasegawa, Miyamoto, Yazaki \& Igarashi, 1981; Fraser \& McNeilly, 1982), the second rise in FSH occurring in the rat on the morning of oestrus and in the ewe cannot be prevented by LH-RH antibody administration after the first FSH surge (Narayana \& Dobson, 1979; Blake \& Kelch, 1981; Hasegawa et al., 1981). Also, plasma FSH levels began to rise after prevention of the preovulatory LH and FSH surge in the ewe (Fraser \& McNeilly, 1982). After injection of $\mathrm{LH}-\mathrm{RH}$ antibodies in the ram, no decline in plasma FSH concentrations was detected during the 24-h study period, despite an immediate fall in LH (Lincoln \& Fraser, 1979). In the male rat, serum FSH values did decline $24 \mathrm{~h}$ after LH-RH antibody administration, but the fall was slower and less pronounced than for LH (Fraser, Sharpe, Lincoln \& Harmer, 1982). Also, in the ovariectomized rat, rhesus monkey and ferret treated with LH-RH antibodies, FSH concentrations decline more slowly than do those of LH (Koch et al., 1973; McCormack, Plant, Hess \& Knobil, 1977; Gledhill, Fraser \& Donovan, 1982).

Maintenance of plasma FSH levels during this time may be due to a number of causes, including, (1) low values of $\mathrm{LH}-\mathrm{RH}$ as a result of incomplete neutralization, (2) autonomous release of FSH, (3), a separate hypothalamic FSH-RH, or (4) changes in secretion of ovarian factors acting directly on the pituitary gonadotrophs during this period. It seems reasonable to assume that small 
amounts of LH-RH will remain biologically active after injection of LH-RH antibodies. Although LH pulses cease, LH is still detectable in the blood and this may reflect low LH-RH stimulation, which also contributes to maintaining FSH release. While evidence for a separate hypothalamic FSH-RH is poor, the pituitary does appear to possess a degree of autonomous FSH release; for example, stimulation of gonadotrophin release by exogenous LH-RH in the ram leads to a rapid decline in plasma LH concentrations when the exogenous stimulus is withdrawn, while FSH values remain elevated for several hours (Lincoln, 1979). In the present study we consider the most important influence on the pattern of FSH observed to be the changes in the levels of ovarian factors which feedback on the pituitary gonadotrophs. This conclusion is supported by studies in the rat which showed that immunoneutralization of LH-RH failed to prevent the rise in serum FSH concentrations which occurs during the first few hours after ovariectomy (Kawakami \& Higuchi, 1979).

The identity of the ovarian factor which suppresses FSH secretion remains to be established. Androgens do not seem to be of primary importance (Dobson \& Ward, 1977) and oestradiol has been implicated as the most likely candidate by Radford, Nancarrow \& Findlay (1978), who also observed maintenance of plasma FSH concentrations with suppressed LH levels after administration of an anaesthetic to ewes during the late follicular phase. In ovariectomized ewes administration of oestradiol suppressed FSH concentrations (Goodman, Pickover \& Karsch, 1981), although these authors proposed that another factor, possibly "inhibin" (Cummins, O'Shea, Bindon, Lee \& Findlay, 1983), also plays a role in the selective suppression of FSH during the normal cycle in the ewe. Our own studies suggest that oestradiol is involved since results from similar experiments on ewes with ovarian transplants have shown that LH-RH immunoneutralization suppresses oestradiol-17ß secretion (A. S. McNeilly, H. M. Fraser \& D. T. Baird, unpublished observations). Studies of sheep pituitaries in vitro have shown that oestradiol-17 $\beta$ can have a direct inhibitory action on the secretion of FSH (Miller, Knight, Grimek \& Gorski, 1977). Also, in ovariectomized ewes actively immunized against LH-RH and with suppressed plasma levels of FSH, these values were reduced even further by administration of oestradiol benzoate (Fraser et al., 1981). Therefore, removal of this negative feedback by reduction in ovarian secretion of oestradiol by LH-RH immunoneutralization probably plays an important part in causing FSH concentrations to rise after LH-RH neutralization, while in control ewes the rising concentrations of oestradiol cause the decline in FSH.

The long-term suppression of ovulatory cycles that we have observed after a single administration of LH-RH antiserum in the present study would agree with similar observations in the rat (Kerdelhue et al., 1976). In contrast, it has been found that, in similar experiments, ovulatory cycles occurred 1-2 weeks after LH-RH antiserum administration in the hamster (de la Cruz et al., 1976), mouse (S. L. Laing, R. E. Gosden \& H. M. Fraser, unpublished observations) and stumptailed macaque monkey (H. M. Fraser, unpublished observations). Such a rapid return of pituitary function would be expected from the time course of decline in LH-RH antibody titres observed in this and other studies and in the return of normal circulating gonadotrophin concentrations after 1-3 weeks in intact and ovariectomized animals (McCormack et al., 1977; Lincoln \& Fraser, 1979; Gledhill et al., 1982; Fraser et al., 1982). We are therefore unable to explain the present results on the basis of continued direct neutralization of LH-RH. As in the study of Kerdelhue et al. (1976), we also observed a tendency for hyperprolactinaemia in the LH-RH antibody-treated ewes, but this did not appear to be a sustained effect and may reflect some disturbance in neurotransmitter activity in response to LH-RH neutralization (McNeilly, 1980). Since the animals were approaching the period of natural anoestrus at this time, perhaps the hypothalamo-pituitary-ovarian axis was particularly sensitive to such disruption.

We thank Mrs M. Swaney, Miss H. Ainslie and Miss N. Anderson for expert technical help, and NIAMDD for the gifts of hormone preparations. 


\section{References}

Arimura, A., Debeljuk, L. \& Schally, A.V. (1974) Blockade of the preovulatory surge of LH and FSH and of ovulation by anti-LH-RH serum in rats. Endocrinology 95, 323-324.

Bäckström, C.T., McNeilly, A.S., Leask, R.M. \& Baird, D.T. (1982) Pulsatile secretion of LH, FSH, prolactin, oestradiol and progesterone during the human menstrual cycle. Clin. Endocr. 17, 29-42.

Blake, C.A. \& Kelch, R.P. (1981) Administration of antiluteinizing hormone-releasing hormone serum to rats: effects on periovulatory secretion of luteinizing hormone and follicle-stimulating hormone. Endocrinology 109, 2175-2179.

Clarke, I.J. \& Cummins, J.T. (1982) The temporal relationship between gonadotropin releasing hormone (GnRH) and luteinizing hormone ( $\mathrm{LH})$ secretion in ovariectomized ewes. Endocrinology 111, $1737-1739$.

Clarke, I.J., Fraser, H.M. \& McNeilly, A.S. (1978) Active immunization of ewes against luteinizing hormone releasing hormone, and its effects on ovulation and gonadotrophin, prolactin and ovarian steroid secretion. $J$. Endocr. 78, 39-47.

Cummins, L.J., O'Shea, T.O., Bindon, B.M., Lee, V.W.K. \& Findlay, J.K. (1983) Ovarian inhibin content and sensitivity to inhibin in Booroola and control strain Merino ewes. J. Reprod. Fert. 67, 1-7.

de la Cruz, A., Arimura, A., de la Cruz, K.G. \& Schally, A.V. (1976) Effect of administration of antiserum to luteinizing hormone-releasing hormone on gonadal function during the estrous cycle in the hamster. Endocrinology 98, 490-497.

Dobson, H. \& Ward, W.R. (1977) Alterations in plasma gonadotrophin patterns caused by sodium pentobarbitone in ewes at oestrus and in anoestrous ewes after infusion of oestradiol. J. Endocr. 75, 109-118.

Ellis, G.B., Desjardins, C. \& Fraser, H.M. (1983) Control of pulsatile LH release in male rats. Neuroendocrinology 37 (in press).

Fraser, H.M. \& McNeilly, A.S. (1982) Effect of immunoneutralization of LHRH on the estrogen-induced $\mathrm{LH}$ and FSH surges in the ewe. Biol. Reprod. 27, 548 . 555.

Fraser, H.M., Clarke, I.J. \& McNeilly, A.S. (1981) Effect of oestrogen and an LH-RH agonist on the release of gonadotrophins in ovariectomized ewes deprived of LH-RH. J. Reprod. Fert. 62, 131-140.

Fraser, H.M., Sharpe, R.M., Lincoln, G.A. \& Harmer, A.J. (1982) LHRH antibodies: their use in the study of hypothalamic LHRH and testicular LHRH-like material, and possible contraceptive applications. In Progress Towards a Male Contraceptive, pp. 41-78. Eds S. L. Jeffcoate \& M. Sandler. John Wiley \& Sons, Ltd, Chichester.

Gledhill, B., Fraser, H.M. \& Donovan, B.T. (1982) Effect of passive immunization against $\mathrm{LH}-\mathrm{RH}$ on gonadotrophin secretion in the ferret. J. Reprod. Fert. 64, 1923.

Goodman, R.L., Pickover, S.M. \& Karsch, F.J. (1981) Ovarian feedback control of follicle-stimulating hormone in the ewe: evidence for selective suppression. Endocrinology 108, 772-777.

Hasegawa, Y., Miyamoto, K., Yazaki, C. \& Igarashi, M. (1981) Regulation of the second surge of folliclestimulating hormone; effects of antiluteinizing hormone-releasing hormone serum and pentobarbital. Endocrinology 109, 130-135.

Kawakami, M. \& Higuchi, T. (1979) Effects of active and passive immunization with LH-RH on gonadotrophin secretion and reproductive function in female rats. Acta endocr., Copenh. 91, 616-628.

Kerdelhue, B., Catin, S., Kordon, C. \& Jutisz, M. (1976) Delayed effects of in vivo LH-RH immunoneutralisation of gonadotropins and prolactin secretion in the female rat. Endocrinology 98, 1539-1549.

Koch, Y., Chobsieng, P., Zor, U., Fridkin, M. \& Lindner, H.R. (1973) Suppression of gonadotrophin secretion and prevention of ovulation in the rat by antiserum to synthetic gonadotrophin-releasing hormone. Biochem. Biophys. Res. Commun. 55, 623-629.

Levine, J.E., Pau, K.Y.F., Ramirez, V.D. \& Jackson, G.L. (1982) Simultaneous measurement of luteinizing hormone-releasing hormone and luteinizing hormone release in unanesthetized, ovariectomized ewes. Endocrinology 111, 1449-1455.

Lincoln, G.A. (1979) Use of a pulsed infusion of luteinizing hormone releasing hormone to mimic seasonally induced endocrine changes in the ram. $J$. Endocr. 83, 251-260.

Lincoln, G.A. \& Fraser, H.M. (1979) Blockade of episodic secretion of luteinizing hormone in the ram by the administration of antibodies to luteinizing hormone releasing hormone. Biol. Reprod. 21, 12391245.

Martensz, N.D., Baird, D.T., Scaramuzzi, R.J. \& Van Look, P.F.A. (1976) Androstenedione and the control of luteinizing hormone in the ewe during anoestrus. $J$. Endocr. 69, 227-237.

McCormack, J.T., Plant, T.M., Hess, D.L. \& Knobil, E. (1977) The effect of luteinizing hormone releasing hormone (LHRH) antiserum administration on gonadotropin secretion in the rhesus monkey. Endocrinology 100, 663-667.

McNeilly, A.S. (1980) Prolactin and the control of gonadotrophin secretion in the female. J. Reprod. Fert. 58, 537-549.

McNeilly, A.S. \& Andrews, P. (1974) Purification and characterization of caprine prolactin. J. Endocr. 60 , 359-367.

McNeilly, J.R., McNeilly, A.S., Walton, J.S. \& Cunningham, F.J. (1976) Development and application of a heterologous radioimmunoassay for ovine folliclestimulating hormone. $J$. Endocr. 70, 69-79.

Miller, W.L., Knight, M.M., Grimek, H.J. \& Gorski, J. (1977) Estrogen regulation of follicle stimulating hormone in cell cultures of sheep pituitaries. Endocrinology 100, 1306-1316.

Narayana, K. \& Dobson, H. (1979) Effect of administration of antibody against $\mathrm{GnRH}$ on preovulatory $\mathrm{LH}$ and FSH surges in the ewe. J. Reprod. Fert. 57, 65-72. 
Radford, H.M., Nancarrow, C.D. \& Findlay, J.K. (1978) Effect of anaesthesia on ovarian folicular development and ovulation in the sheep subsequent to prostaglandin-induced luteolysis. J. Endocr. 78, 321327.

Scaramuzzi, R.J., Corker, C.S., Young, G. \& Baird, D.T. (1975) Production of antisera to steroid hormones in sheep. In Steroid Immunoassay, pp. 111-122. Eds E. H. D. Cameron, S. G. Hillier \& K. Griffiths. Alpha Omega Alpha, Cardiff.

Snabes, M.C. \& Kelch, R.P. (1979) Acute inhibitory effects of antiserum to gonadotrophin-releasing hormone in ovariectomized rats. Neuroendocrinology 29, $34-41$.

Received 28 February 1983 